\title{
THE COVID-19 PANDEMIC AND INDIAN PHARMACEUTICAL COMPANIES: AN EVENT STUDY ANALYSIS
}

\author{
Chinmaya Behera* and Badri Narayan Rath** \\ ${ }^{*}$ Corresponding author. Economics and General Management, Goa Institute of Management, Goa-403505, \\ India. Email: chinmayaeco@gmail.com \\ ** Department of Liberal Arts, IIT Hyderabad, Kandi, Sangareddy, India. \\ Email: badri@la.iith.ac.in
}

\begin{abstract}
Although there is a plethora of studies which examine the impact of the COVID-19 pandemic on India's financial sector, we contribute by investigating the effect of the ongoing COVID-19 pandemic on stock returns of Indian pharmaceutical companies. By employing an event study methodology, our results indicate that the average returns of the pharmaceutical sector are positive during the COVID-19 phase although mixed evidence is found at the firm level. This finding is also robust to alternative model specifications.
\end{abstract}

Keywords: COVID-19; Pharmaceutical companies; Risk; Stock return; Event study analysis. JEL Classifications: G11; G15; G18.

Article history:

Received : October 04, 2020

Revised : January 12, 2021

Accepted : January 17, 2021

Available Online : January 31, 2021

https://doi.org/10.21098/bemp.v24i0.1483 


\section{INTRODUCTION}

India's pharmaceutical industry is important for its economic growth. The industry is also a global leader. The Indian pharmaceutical sector is ranked $3^{\text {rd }}$ in terms of volume and $14^{\text {th }}$ in terms of value (Gopalakrishnan and Vijay, 2017). The pharmaceutical industry also contributes around $4 \%$ to India's GDP and generates significant employment. However, the ongoing COVID-19 pandemic has adversely affected almost all sectors of the Indian economy (Dev and Sengupta, 2020; Mishra, Rath and Dash, 2020; Rath and Akram, 2020; Prabheesh, 2020). ${ }^{1}$

The aim of this paper is to examine the impact of the COVID-19 pandemic on the Indian pharmaceutical industry. We focus on the pharmaceutical industry because of the following reasons. First, the Indian pharmaceutical industry is entirely transformed in terms of its production capacity, innovation and adoption of technologies from mid-1990s (Kale, 2019; Kale and Little, 2007; Athreve and Godley, 2009). Second, the government of India provides the fiscal incentives for pursuing research and development and came up with specific trade related intellectual property rights to boost exports, which significantly improved the productivity of the Indian pharmaceutical industry (Sharma, 2012). Third, since several countries aim to develop a COVID-19 vaccine, the Ministry of Health and Family Welfare (MoHFW) of the Government of India has been providing various incentives and support to Indian pharmaceutical companies. These incentives are likely to have a positive impact on this sector.

Figure 1.

\section{Output and Employment Growth Rates of Pharmaceutical Industry}

This figure illustrates output growth as well as employment growth rates of Indian pharmaceutical industry during 2010 to 2019.

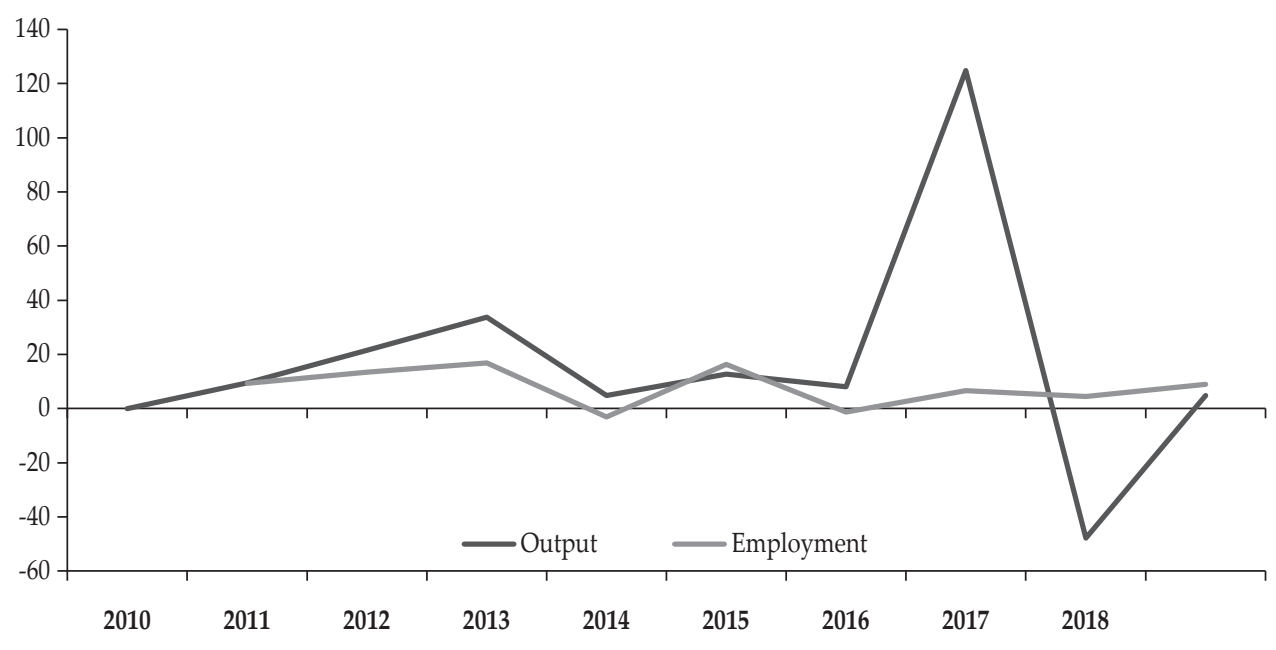

Source: CEIC database.

1 There are sectoral analysis for other countries as well, see He, Sun, Zhang \& Li (2020) and He, Niu, Sun \& Li (2020). 
Figure 2.

Daily Average Stock Closing Price of Pharmaceutical Industry

This figure presents the daily average stock closing prices of pharma companies.

Pharma Index

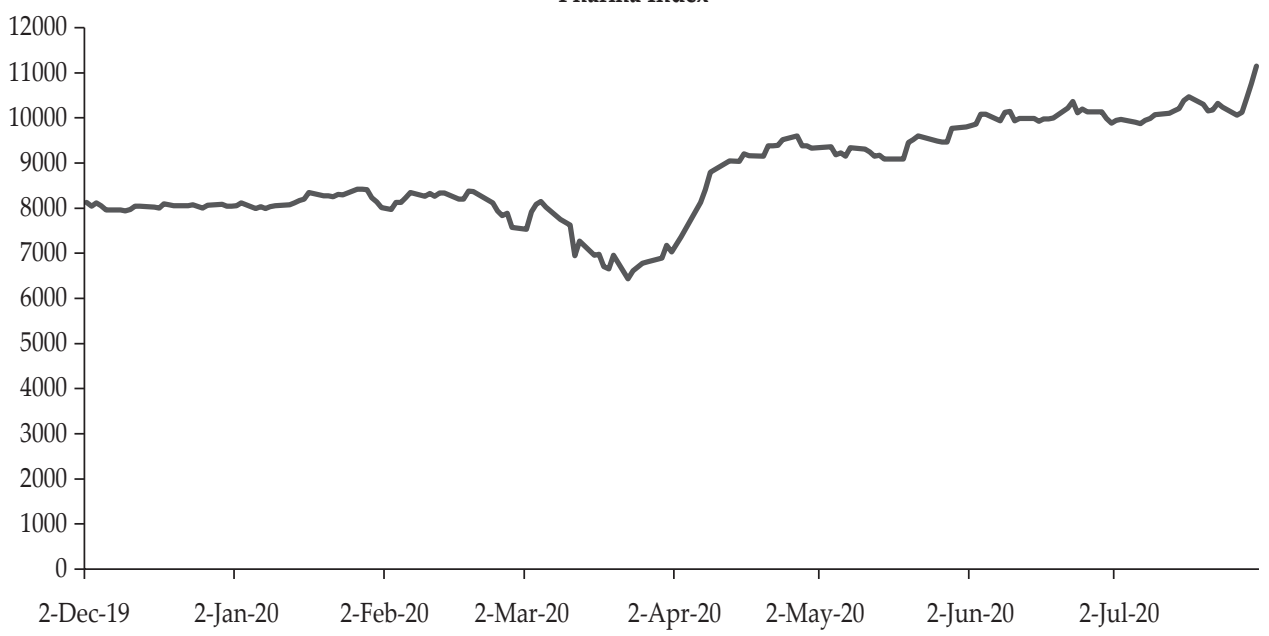

Source: National Stock Exchange, India.

Fourth, the overall performance of the Indian pharmaceutical industry, both in terms of output and employment, is impressive, particularly during 2010s (see Figure 1). Similarly, the average price of pharmaceutical stocks in India shows an upward trend during the COVID-19 period (see Figure 2).

There is an emerging literature on the effects of COVID-19, such as on the financial markets, energy markets, and various sectors of the economy. The main conclusion of these studies is that the global financial risk has not only increased substantially due to the COVID-19 pandemic but has also negatively affected stock and oil prices.

In this literature, however, there are only a few studies which examine the impact of COVID-19 on firm or industry level performance. Some exceptions are Shen et al. (2020), Gu et al. (2020), He et al. (2020), and Seungho et al. (2020). Shen et al. (2020) investigate the impact of the COVID-19 pandemic on firm performance by using financial data of Chinese companies. They find that COVID-19 negatively affects firm performance. Similarly, Seungho et al. (2020) examine the effect of COVID-19 on stock market volatility and find both negative and positive impacts of COVID-19. In the case of India: (a) Mishra et al. (2020) examine the impact of COVID-19 and find that it negatively impacts the Indian financial market; and (b) Rath and Akram (2020) show that the COVID-19 pandemic caused electricity spot price. $^{2}$

\footnotetext{
2 While we do not undertake a formal literature review, we refer interested readers to special issues of some journals such as Emerging Markets Finance and Trade (see Sharma \& Sha, 2020; Sha \& Sharma, 2020; Phan \& Narayan, 2020); Energy Research Letters (see Narayan, 2020a; Devpura \& Narayan, 2020); Asian Economics Letters (see Devpura, 2020; Narayan, 2020a,b; Sharma, 2020; Iyke, 2020). We only refer to dedicated special issue papers rather than individual journal papers as on this there are many papers.
} 
One gap in this literature is with regard to the lack of emphasis on how COVID-19 has impacted the pharmaceutical industry. This paper aims to fill this research gap. Our goal is to examine whether the COVID-19 outbreak affects abnormal returns and cumulative abnormal returns of the Indian pharmaceutical industry.

The novelties of this study are as follows. First, studies on the impact of the COVID-19 pandemic on the Indian economy to-date have mostly focused at the macro level but our study focuses on the impact of COVID-19 at the micro level. We purposively pick the pharmaceutical industry because the performance of this industry during the pandemic is likely to be different as compared to other industries given that this industry is actively involved in recovery and mitigating efforts following the onset of the pandemic. Second, we also compare the effect of the COVID-19 pandemic on abnormal returns of automobile and realty sectors. Both automobile and realty sectors are severely affected by the pandemic. Therefore, we aim to find whether our results for the pharmaceutical sector differ from those two sectors. Third, we consider COVID-19 as an event and employ an event study methodology to examine the impact of COVID-19 on the pharmaceutical companies in India. Our study extends the work of Ramelli and Wagner (2020), and Yan (2020) by conducting an event study to examine the impact of the pandemic shock. The difference is we focus on the pharmaceutical stock returns of India.

We find that the average abnormal returns of the pharmaceutical sector are positive and statistically significant. The average cumulative abnormal returns are also positive and statistically significant for the pharmaceutical industry. However, when we analyze individual firms, mixed evidence (sign wise) on abnormal returns are noticed due to COVID-19. We also use the Fama and French (1993) 3 -factor model to examine the impact of firm-specific events on returns. Finally, we use sectoral indices (pharma, auto and reality) to examine the robustness of our results. We find a mixed response (both positive and negative signs) of returns for pharma, auto and reality sectors, which is consistent with the results from the firm level analysis.

The remaining sections of this paper are as follows. Section II presents the data and methodology. The empirical results are discussed in section III and section IV concludes.

\section{DATA AND METHODOLOGY}

This study is based on secondary data by emphasizing on nine pharmaceutical firms, which are chosen based on market capitalization. Further, we consider the CNX Nifty index returns as a proxy for market returns as it has the highest trading volume. The closing price of the nine pharmaceuticals and the key indices (pharma, auto and realty sectors) are collected from the Center for Monitoring Indian Economy (CMIE) database for the period December 03, 2019 to May 28, 2020. The sample is based on availability of data. We consider January 30 as an event day as the MoHFW officially reported the first COVID-19 positive case in India. Furthermore, we consider 10 days pre- and post-event days for the analysis (Kritzman, 1994). To analyze the Fama and French 3-factor model, we collect 
Small-Minus-Big (SMB) and High-Minus-Low (HML) data from Agarwalla et al. (2013). Further, the 91-day Treasury bill rate data are collected from the Reserve Bank of India database for the analysis.

The paper uses an event study approach and the Fama and French 3-factor model to study the impact of COVID-19 on pharmaceutical firms' returns. Each methodology is described in detail as follows:

\section{A. Event Study}

We consider the COVID-19 pandemic as an event and study its impact on return series for the pharmaceutical companies. As the first COVID-19 case is reported on January 30, 2020 by the MoHFW and hence the present study considers that as the event day. Furthermore, ten days before and after the event day are considered as a window period. Similarly, December 3, 2019 to January 15, 2020 is considered a window estimation period.

We calculate normal, abnormal, and cumulative abnormal returns during the estimation window period based on the following model:

$$
R_{i t}=\alpha_{i}+\beta_{i} R_{m t}+\varepsilon_{i t}
$$

In equation $1, R_{i t}$ is the pharmaceutical stock price return, where $i=1 \ldots 9$ at time period $t$ and $R_{m t}$ refers to market return, $m=1$ and $\varepsilon_{i t}$ means error term $i=1 \ldots 9$. They are the parameters to be estimated. We then calculate abnormal returns $(A R)$ and cumulative abnormal returns (CAR) using equation 2 as:

$$
A R_{i t}=R_{i t}-E R_{i t} \text { and } C A R_{i}=\sum_{t=1}^{n} A R_{i t}
$$

Where $E R_{i t}$ stands for expected returns and $i=1 \ldots 9$ at time period $t$.

\section{B. Fama and French 3-Factor Model}

Next, the Fama and French (1993) 3-factor model is used to check the impact of firm-specific events on return series. In this regard, to capture other commonly known market risks, which are shown to be relevant (see, for instance, Narayan et al. 2017), we employ the following model:

$$
R_{i t}-R_{f t}=\alpha_{i}+\beta_{i}\left(R_{m t}-R_{f t}\right)+\gamma_{i} S M B_{t}+\delta_{i} H M L_{t}+\varepsilon_{i t}
$$

In Equation 3, $R_{i t}$ refers to asset return over time, $t$ where $i=1,2 \ldots 9, R_{f t}$ is the risk free interest rate which is the 3-month Treasury bill rate, $R_{m t}$ refers to the CNX Nifty returns over time $t, S M B_{t}$ is difference between small portfolios and big portfolios, $H M L_{t}$ is the difference between high value portfolio and small value portfolio. 


\section{EMPIRICAL RESULTS}

In this section, we analyze $A R$ and $C A R$ obtained for the nine pharmaceutical firms. Table 1 reports the $A R$ of Alkem Laboratories, Abbott India Ltd, and Aurobindo companies. For Alkem Laboratories, we see a positive and statistically significant $A R$ in the post-COVID day. One likely reason could be higher demand for pharmaceutical products during the pandemic; hence, a higher share price. On the other hand, the $A R$ of Abbott India and Aurobindo show mixed results (both positive and negative returns) in the post-COVID period.

Table 1.

\section{Results of Alkem Labourites, Abbott India, and Aurobindo Companies}

This table has abnormal returns $(A R)$ and the corresponding $t$-statistics for Alkem Labourites, Abbott India, and Aurobindo. Finally, ${ }^{*}$ and ${ }^{* *}$ denote statistical significance at the $1 \%$ and $5 \%$ levels, respectively.

\begin{tabular}{lcccccc}
\hline EVENT & \multicolumn{2}{c}{ ALKEM } & \multicolumn{2}{c}{ ABBOTT } & \multicolumn{2}{c}{ AUROBINDO } \\
\cline { 2 - 7 } WINDOW & AR & $t$-statistics & AR & $t$-statistics & AR & $t$-statistics \\
\hline E-10 & -0.00 & -0.51 & -0.01 & -1.06 & -0.02 & -1.65 \\
E-9 & -0.01 & -1.25 & -0.00 & -0.27 & 0.01 & 1.40 \\
E-8 & 0.00 & 0.42 & 0.01 & 1.30 & 0.00 & 0.52 \\
E-7 & -0.00 & -0.45 & 0.00 & 0.83 & 0.02 & 1.83 \\
E-6 & -0.00 & -0.22 & 0.00 & 0.33 & 0.01 & 1.10 \\
E-5 & -0.01 & -1.54 & -0.00 & -0.29 & -0.02 & -1.85 \\
E-4 & 0.00 & 0.17 & -0.01 & -1.05 & 0.01 & 0.89 \\
E-3 & 0.00 & 0.03 & 0.01 & 1.22 & 0.03 & $2.36^{*}$ \\
E-2 & -0.01 & -1.50 & 0.00 & 0.32 & -0.00 & -0.52 \\
E-1 & -0.01 & -1.32 & -0.00 & -0.32 & -0.00 & -0.27 \\
\hline E-0 & -0.00 & -0.48 & -0.00 & -0.37 & -0.04 & $-3.17^{* *}$ \\
\hline E+1 & 0.03 & $3.23^{* *}$ & 0.00 & 0.34 & 0.00 & 0.69 \\
E+2 & -0.01 & -0.96 & 0.03 & $3.15^{* *}$ & 0.01 & 0.93 \\
E+3 & -0.00 & -0.76 & 0.01 & 1.14 & 0.00 & 0.63 \\
E+4 & 0.00 & 0.10 & -0.01 & -0.90 & 0.01 & 0.81 \\
E+5 & -0.00 & -0.02 & -0.00 & -0.02 & -0.00 & -0.17 \\
E+6 & 0.03 & $3.12^{*}$ & 0.07 & $6.59^{*}$ & 0.07 & $5.04^{*}$ \\
E+7 & 0.02 & $2.32^{*}$ & 0.05 & $4.42^{*}$ & -0.00 & -0.09 \\
E+8 & 0.01 & 1.13 & -0.02 & $-2.19^{*}$ & 9.59 & 0.00 \\
E+9 & -0.00 & -0.16 & 0.01 & 1.22 & -0.01 & -1.31 \\
E+10 & -0.01 & -1.31 & 0.005 & 0.50 & -0.03 & $-2.18^{*}$ \\
\hline
\end{tabular}

The $A R$ of Cipla, Dr. Reddy and Lupin are reported in Table 2. It is observed that COVID-19 has a positive impact on $A R$ of Cipla and Dr. Reddy. However, during the pre-COVID period, $A R$ of Lupin Dr. Reddy was also statistically significant. 
Table 2.

\section{Results of Cipla, Dr. Reddy and Lupin Companies}

This table has abnormal returns $(A R)$ and the corresponding $t$-statistics for Cipla, Dr. Reddy and Lupin. Finally, ${ }^{*}$ and ** denote statistical significance at the $1 \%$ and $5 \%$ levels, respectively.

\begin{tabular}{lcccccc}
\hline EVENT & \multicolumn{2}{c}{ CIPLA } & \multicolumn{2}{c}{ DR. REDDY } & \multicolumn{2}{c}{ LUPIN } \\
\cline { 2 - 7 } WINDOW & AR & $t$-statistics & AR & $t$-statistics & AR & $t$-statistics \\
\hline E-10 & -0.00 & -0.90 & 0.00 & 0.64 & 0.00 & 0.68 \\
E-9 & -0.00 & -0.04 & 0.03 & 3.62 & 0.01 & $2.47^{* *}$ \\
E-8 & 0.00 & 0.57 & 0.00 & 1.06 & -0.03 & $-4.25^{* *}$ \\
E-7 & -0.01 & -1.17 & 0.00 & 0.04 & 0.01 & 2.31 \\
E-6 & -0.00 & -0.11 & 0.00 & 0.09 & 0.00 & 0.44 \\
E-5 & -0.01 & -1.82 & -0.00 & -1.05 & -0.00 & -0.50 \\
E-4 & -0.01 & -1.78 & -0.00 & -0.41 & 0.00 & 0.04 \\
E-3 & 0.01 & 1.81 & 0.05 & 5.87 & 0.02 & $3.58^{* *}$ \\
E-2 & 0.00 & 0.32 & 0.00 & 0.04 & 0.00 & 0.16 \\
E-1 & -0.01 & -1.14 & -0.01 & -1.63 & -0.00 & -0.85 \\
\hline E-0 & -0.01 & -1.84 & 0.00 & 0.31 & -0.01 & -1.63 \\
\hline E+1 & -0.00 & -0.57 & -0.01 & -1.41 & -0.00 & -0.74 \\
E+2 & 0.00 & 0.80 & 0.012 & 1.39 & 0.00 & 1.14 \\
E+3 & -0.00 & -0.71 & 0.02 & $3.00^{* *}$ & -0.00 & -0.10 \\
E+4 & -0.00 & -0.86 & -0.03 & $-4.08^{*}$ & -0.00 & -0.61 \\
E+5 & -0.02 & $-2.09^{*}$ & 0.00 & 0.78 & -0.00 & -0.27 \\
E+6 & 0.00 & 0.93 & 0.00 & 0.27 & -0.01 & -1.86 \\
E+7 & 0.00 & 0.63 & -0.00 & -0.59 & -0.00 & -0.05 \\
E+8 & 0.00 & 0.80 & 0.01 & 1.33 & 0.00 & 0.11 \\
E+9 & -0.01 & -1.41 & -0.00 & -0.03 & -0.00 & -0.94 \\
E+10 & -0.00 & -0.68 & 0.03 & $4.46^{* *}$ & 0.00 & 0.60 \\
\hline & & & & & &
\end{tabular}

Table 3 reports the return series of Sun Pharma, Torrent, and Zydus Wellness. The COVID-19 pandemic has impacted Sun Pharma and Torrent. However, during the pre-COVID period, the $A R$ of Zydus wellness was statistically significant. This indicates that the firm-specific events do play a major role in $A R$.

Table 3.

\section{Results of Sun Pharma, Torrent and Zydus Wellness Companies}

This table has abnormal returns $(A R)$ and the corresponding $t$-statistics for Sun Pharma, Torrent and Zydus. Finally, ${ }^{*}$ and ${ }^{* *}$ denote statistical significance at the $1 \%$ and $5 \%$ levels, respectively.

\begin{tabular}{lcccccc}
\hline EVENT & \multicolumn{2}{c}{ SUN PHARMA } & \multicolumn{2}{c}{ TORRENT } & \multicolumn{2}{c}{ ZYDUS } \\
\cline { 2 - 7 } WINDOW & AR & $\boldsymbol{t}$-statistics & AR & $\boldsymbol{t}$-statistics & AR & $t$-statistics \\
\hline E-10 & -0.00 & -0.90 & 0.00 & 0.64 & 0.00 & 0.68 \\
E-9 & -0.00 & -0.04 & 0.03 & 3.62 & 0.01 & $2.47^{* *}$ \\
E-8 & 0.00 & 0.57 & 0.00 & 1.06 & -0.03 & $-4.25^{* *}$ \\
E-7 & -0.01 & -1.17 & 0.00 & 0.04 & 0.01 & 2.31 \\
E-6 & -0.00 & -0.11 & 0.00 & 0.09 & 0.00 & 0.44 \\
E-5 & -0.01 & -1.82 & -0.00 & -1.05 & -0.00 & -0.50 \\
E-4 & -0.01 & -1.78 & -0.00 & -0.41 & 0.00 & 0.04 \\
\hline
\end{tabular}


Table 3.

Results of Sun Pharma, Torrent and Zydus Wellness Companies (Continued)

\begin{tabular}{lcccccc}
\hline EVENT & \multicolumn{2}{c}{ SUN PHARMA } & \multicolumn{2}{c}{ TORRENT } & \multicolumn{2}{c}{ ZYDUS } \\
\cline { 2 - 7 } WINDOW & AR & $\boldsymbol{t}$-statistics & AR & $\boldsymbol{t}$-statistics & AR & $\boldsymbol{t}$-statistics \\
\hline E-3 & 0.01 & 1.81 & 0.05 & 5.87 & 0.02 & $3.58^{* *}$ \\
E-2 & 0.00 & 0.32 & 0.00 & 0.04 & 0.00 & 0.16 \\
E-1 & -0.01 & -1.14 & -0.01 & -1.63 & -0.00 & -0.85 \\
\hline E-0 & -0.01 & -1.84 & 0.00 & 0.31 & -0.01 & -1.63 \\
\hline E+1 & -0.00 & -0.57 & -0.01 & -1.41 & -0.00 & -0.74 \\
E+2 & 0.00 & 0.80 & 0.012 & 1.39 & 0.00 & 1.14 \\
E+3 & -0.00 & -0.71 & 0.02 & $3.00^{* *}$ & -0.00 & -0.10 \\
E+4 & -0.00 & -0.86 & -0.03 & $-4.08^{*}$ & -0.00 & -0.61 \\
E+5 & -0.02 & $-2.09^{*}$ & 0.00 & 0.78 & -0.00 & -0.27 \\
E+6 & 0.00 & 0.93 & 0.00 & 0.27 & -0.01 & -1.86 \\
E+7 & 0.00 & 0.63 & -0.00 & -0.59 & -0.00 & -0.05 \\
E+8 & 0.00 & 0.80 & 0.01 & 1.33 & 0.00 & 0.11 \\
E+9 & -0.01 & -1.41 & -0.00 & -0.03 & -0.00 & -0.94 \\
E+10 & -0.00 & -0.68 & 0.03 & $4.46^{* *}$ & 0.00 & 0.60 \\
\hline
\end{tabular}

The CAR of all nine firms are reported in Table 4. We observe that COVID-19 has a positive impact on Abott India and Torrent, and a negative impact on Sun Pharma. Further, majority the companies are showing a positive CAR during the estimation window period. However, the existence of a negative $C A R$ contradicts the previous literature. Further, to get conclusive results, we use pharmaceutical average for our analysis. The results are reported in Table 4 . We find that COVID-19 has a positive impact on CAR of pharmaceutical firms. Therefore, we can conclude that the COVID-19 pandemic does affect the pharmaceutical sector positively. The finding of our study aligns with the observation made by Dondelli et al. (2017).

Table 4.

\section{Cumulative Abnormal Return}

This table has abnormal returns $(A R)$ and the corresponding $t$-statistics for all nine firms. Finally, ${ }^{*}$ and ${ }^{* *}$ denote statistical significance at the $1 \%$ and $5 \%$ levels, respectively.

\begin{tabular}{|c|c|c|c|c|c|c|}
\hline \multirow[t]{2}{*}{ Company Name } & \multicolumn{2}{|c|}{ Pre-Event (10 days) } & \multicolumn{2}{|c|}{ Post-Event (10 days) } & \multicolumn{2}{|c|}{$\begin{array}{c}\text { Window Period } \\
\text { (21 days) }\end{array}$} \\
\hline & $C A R$ & $t$-statistics & $C A R$ & $t$-statistics & CAR & $t$-statistics \\
\hline Alkem Laborites & -0.06 & -1.72 & 0.04 & 1.28 & 0.00 & 0.16 \\
\hline Abbott India & 0.01 & 0.36 & 0.16 & $5.21^{* *}$ & 0.17 & $3.75^{* *}$ \\
\hline Aurobindo & 0.05 & 1.31 & 0.06 & 1.50 & 0.07 & 1.72 \\
\hline Cipla & -0.04 & -1.51 & -0.03 & -1.11 & -0.09 & $-2.26^{*}$ \\
\hline Dr. Reddy & 0.07 & $2.96^{* *}$ & 0.04 & 1.83 & 0.12 & $3.38^{* *}$ \\
\hline Lupin & 0.03 & 1.17 & -0.02 & -0.78 & -0.00 & -0.05 \\
\hline Sun Pharma & 0.00 & 0.21 & -0.06 & $-2.15^{*}$ & -0.07 & -1.65 \\
\hline Torrent & 0.03 & 1.17 & 0.07 & $2.53^{* *}$ & 0.11 & $2.62^{* *}$ \\
\hline Zydus Wellness & 0.02 & 1.02 & -0.02 & -0.88 & -0.00 & -0.17 \\
\hline Average & 0.01 & 0.64 & 0.10 & $4.49^{* *}$ & 0.11 & $3.53^{* *}$ \\
\hline
\end{tabular}


After obtaining mixed responses of CAR by considering COVID-19 as an event, we attempt to examine the impact of lockdown due to COVID-19 on CAR in the case of pharmaceutical firms. The lockdown in India started on March 25, 2020. The CAR results are reported in Table 5. We find that lockdown has a positive impact on majority the pharmaceutical firms. Further, during the estimation window periods, the majority of pharmaceutical firms show a positive CAR because of the lockdown. Finally, the lockdown also has a positive impact on the CAR of pharmaceutical industry. Therefore, we find that both the COVID-19 and the resulting lockdown in India have had a positive impact on the pharmaceutical industry.

Table 5.

\section{Cumulative Abnormal Return}

India officially started lockdown on 24/03/2021. We calculate cumulative abnormal returns (CAR) and the corresponding $t$-statistics for all nine pharma firms by taking the lockdown as an event. This table has these results. Finally, ${ }^{*}$ and ${ }^{* *}$ denote statistical significance at the $1 \%$ and $5 \%$ levels, respectively.

\begin{tabular}{|c|c|c|c|c|c|c|}
\hline \multirow{2}{*}{ Company Name } & \multicolumn{2}{|c|}{ Pre-Event (10 days) } & \multicolumn{2}{|c|}{ Post-Event (10 days) } & \multicolumn{2}{|c|}{$\begin{array}{c}\text { Window Period } \\
\text { (21 days) }\end{array}$} \\
\hline & CAR & $t$-statistics & $C A R$ & $t$-statistics & CAR & $t$-statistics \\
\hline Alkem Laborites & -0.09 & $-2.29 * *$ & 0.01 & $2.91^{*}$ & 0.00 & 0.12 \\
\hline Abbott India & 0.02 & $2.64^{*}$ & 0.14 & $3.04^{*}$ & 0.29 & $4.27^{*}$ \\
\hline Aurobindo & -0.02 & -0.31 & 0.10 & 0.82 & 0.13 & 1.09 \\
\hline Cipla & 0.08 & $2.11^{* *}$ & 0.31 & $7.53^{*}$ & 0.39 & $6.47^{*}$ \\
\hline Dr. Reddy & -0.08 & $-1.92^{* *}$ & 0.20 & $4.77^{*}$ & 0.15 & $2.40^{*}$ \\
\hline Lupin & 0.02 & 0.58 & 0.20 & $5.39^{*}$ & 0.24 & $4.47^{*}$ \\
\hline Sun Pharma & -0.00 & -0.47 & 0.20 & $4.71^{*}$ & 0.23 & $3.61^{*}$ \\
\hline Torrent & -0.06 & -1.54 & 0.29 & $6.66^{*}$ & 0.11 & $2.62^{*}$ \\
\hline Zydus Wellness & -0.01 & -1.59 & 0.08 & 1.68 & 0.12 & $3.41^{*}$ \\
\hline Average & 0.05 & 1.47 & 0.23 & $6.72^{*}$ & 0.16 & $4.83^{*}$ \\
\hline
\end{tabular}

We also analyze whether any specific market risk factors had any role in influencing abnormal returns. Therefore, we apply the Fama and French 3-factor model, where we add $S M B$ and $H M L$ to the model. The results are reported in Table 6 . We find that market risk factors affect the individual return series. Further, firm size affects the firm return series positively and statistically significantly in the case of Cipla. 
Table 6.

Fama and French 3-factor Model

This table reports results of the Fama and French 3-factor model, where EMR is the expected market risk, SMB is the size factor and $H M L$ is the value factor, respectively. The $t$-statistic is reported in parenthesis. Finally, ${ }^{*}$ and ${ }^{* * *}$ denote statistical significance at the $1 \%$ and $10 \%$ levels, respectively.

\begin{tabular}{lcccccccc}
\hline Firm & constant & $t$-statistics & $E M R$ & $t$-statistics & $S M B$ & $t$-statistics & $H M L$ & $t$-statistics \\
\hline Abott & -0.25 & -2.56 & $0.83^{*}$ & 13.70 & -0.01 & -0.59 & 0.02 & 0.89 \\
Alkem & -0.27 & 2.62 & $0.82^{*}$ & 12.45 & 0.015 & 0.64 & 0.00 & 0.09 \\
Aurobindo & 0.16 & 1.08 & $1.10^{*}$ & 11.84 & $0.065^{* * *}$ & 1.86 & -0.06 & -1.58 \\
Cipla & -0.06 & -0.61 & $0.95^{*}$ & 14.44 & 0.01 & 0.73 & 0.00 & 0.03 \\
Dr. Reddy & -0.11 & -1.36 & $0.92^{*}$ & 17.22 & 0.00 & 0.34 & 0.00 & 0.19 \\
Lupin & -0.11 & -0.92 & $0.92^{*}$ & 12.77 & 0.01 & 0.54 & 0.00 & 0.01 \\
Sun Pharma & -0.01 & -0.19 & $0.98^{*}$ & 17.76 & 0.00 & 0.41 & -0.00 & -0.06 \\
Torrent & -0.28 & -2.68 & $0.82^{*}$ & 12.64 & 0.02 & 0.86 & -0.01 & -0.47 \\
Zydus & -0.36 & -3.57 & $0.77^{*}$ & 12.19 & 0.01 & 0.64 & -0.00 & -0.01 \\
\hline
\end{tabular}

\section{A. Robustness Check}

Finally, to check the robustness, we consider the return series of pharma index. Then, we apply the event study on the return series. Results are reported in Table 7. We find the event has both positive and negative effects on returns of the pharma index which is consistent with the results from the firm level analysis. Furthermore, we compare the pharma index with the auto and reality indices to see the impact of the COVID-19 pandemic. We find that COVID-19 has impacted auto and reality indices. Further, we calculate the CAR of all three indices. The results are reported in Table 8, and indicate that COVID-19 has had a negative impact only on the reality sector.

Alternatively, following Narayan et al. (2017), we use buy-and-hold abnormal return (BHAR) method for the robustness of the results. The BHAR for a pharmaceutical stock $i$ over an interval trading day between $T_{1}$ and $T_{2}$ is calculated as follows:

$$
B H A R_{i, T_{2} T_{2}}=\left[\prod_{t=T_{1}}^{T_{2}}\left(1+R_{i t}\right)-\prod_{t=T_{1}}^{T_{2}}\left(1+R_{m t}\right)\right]
$$

where $B H A R_{i, T_{2} T_{2}}$ is the BHAR for firm $i$ over an interval of trading days between $T_{1}$ and $T_{2} ; R_{i t}$ is the actual returns for pharmaceutical company $i$ at time $t$; and $R_{m t}$ is the actual market returns at time $t$. The results are reported in Table 9. We notice that the results are consistent with those obtained from the event study approach. 
Table 7.

\section{Results of Abnormal Returns from Pharma, Auto and Reality Indices}

This table has abnormal returns $(A R)$ and the corresponding $t$-statistics for Pharma, Auto and Reality sectors. Finally, * and ** denote statistical significance at the $1 \%$ and $5 \%$ levels, respectively.

\begin{tabular}{lcccccc}
\hline EVENT & \multicolumn{2}{c}{ PHARMA } & \multicolumn{2}{c}{ Auto } & \multicolumn{2}{c}{ Reality } \\
\cline { 2 - 7 } WINDOW & $A R$ & $t$-statistics & $A R$ & $t$-statistics & $A R$ & $t$-statistics \\
\hline E-10 & 0.00 & 0.50 & -0.00 & -0.01 & 0.00 & 0.63 \\
E-9 & 0.01 & $1.98^{* *}$ & 0.00 & 0.46 & 0.00 & 0.05 \\
E-8 & -0.00 & -0.28 & 0.00 & 0.80 & 0.01 & 1.35 \\
E-7 & 0.00 & 0.41 & -0.00 & -0.61 & -0.01 & -0.91 \\
E-6 & 0.00 & 0.16 & -0.00 & -0.11 & 0.00 & 0.33 \\
E-5 & 0.00 & 0.26 & -0.00 & -0.04 & 0.01 & 1.22 \\
E-4 & -0.00 & -0.37 & -0.00 & -0.48 & -0.00 & -0.31 \\
E-3 & 0.02 & 2.36 & 0.01 & 1.58 & 0.00 & 0.42 \\
E-2 & 0.00 & 0.45 & -0.00 & -0.44 & 0.00 & 0.46 \\
E-1 & -0.00 & -0.42 & -0.00 & -0.16 & -0.00 & -0.21 \\
\hline E-0 & -0.01 & -1.77 & 0.00 & 0.81 & 0.00 & 0.29 \\
\hline E+1 & -0.00 & -0.87 & -0.00 & -0.20 & 0.01 & 1.55 \\
E+2 & -0.00 & -0.02 & 0.01 & 1.51 & -0.05 & $-4.94^{*}$ \\
E+3 & -0.00 & -0.82 & 0.00 & 0.82 & 0.01 & 1.00 \\
E+4 & 0.00 & 0.73 & -0.02 & $-2.34^{* *}$ & 0.00 & 0.22 \\
E+5 & -0.00 & -0.47 & -0.01 & -1.10 & 0.01 & 1.22 \\
E+6 & 0.01 & 1.19 & -0.00 & -0.52 & -0.00 & -0.47 \\
E+7 & 0.01 & 1.79 & -0.00 & -0.46 & -0.01 & -1.38 \\
E+8 & -0.00 & -0.65 & -0.01 & -1.81 & -0.00 & -0.43 \\
E+9 & 0.00 & 0.50 & -0.00 & -0.61 & -0.00 & -0.45 \\
E+10 & -0.01 & -1.21 & -0.00 & -0.71 & -0.01 & -1.50 \\
\hline
\end{tabular}

Table 8.

\section{Cumulative Abnormal Returns of Three Indices}

This table has cumulative abnormal returns and the corresponding $t$-statistics of Pharma, Auto and Reality sectors. Finally, ${ }^{*}$ denotes statistical significance at the $1 \%$ level.

\begin{tabular}{|c|c|c|c|c|c|c|}
\hline \multirow[t]{2}{*}{ Index } & \multicolumn{2}{|c|}{ Pre-Event (10 days) } & \multicolumn{2}{|c|}{ Post-Event (10 days) } & \multicolumn{2}{|c|}{$\begin{array}{c}\text { Window Period } \\
\text { (21 days) }\end{array}$} \\
\hline & CAR & $t$-statistics & $C A R$ & $t$-statistics & CAR & $t$-statistics \\
\hline Pharma & 0.04 & 1.47 & 0.00 & 0.04 & 0.04 & 0.92 \\
\hline Auto & 0.00 & 0.20 & -0.05 & -1.16 & -0.03 & -0.54 \\
\hline Reality & -0.54 & $-13.97^{*}$ & -0.05 & -1.51 & -0.02 & -0.37 \\
\hline
\end{tabular}


Table 9.

Results of BHAR

This table has the BHAR results and the corresponding $t$-statistics for Pharma, Auto and Reality sectors. Finally, *** denote statistical significance at the $10 \%$ level.

\begin{tabular}{lcccccc}
\hline \multirow{2}{*}{ Index } & \multicolumn{2}{c}{ Pre-Event (10 days) } & \multicolumn{2}{c}{ Post-Event (10 days) } & \multicolumn{2}{c}{$\begin{array}{c}\text { Window Period } \\
\text { (21 days) }\end{array}$} \\
\cline { 2 - 7 } & CAR & t-statistics & CAR & $t$-statistics & CAR & $t$-statistics \\
\hline Pharma & 0.04 & $1.52^{* * *}$ & -0.01 & 0.33 & $0-02$ & 0.52 \\
Auto & 0.00 & 0.84 & -0.04 & $-1.50^{* * *}$ & -0.04 & -1.00 \\
Reality & 0.04 & 1.04 & -0.05 & $-1.38^{* * *}$ & -0.01 & -0.18 \\
\hline
\end{tabular}

\section{CONCLUSION}

The literature on the effects of COVID-19 is evolving; however, to the best of our knowledge, none of the previous studies have examined the impact of COVID-19 pandemic on the Indian pharmaceutical sector. Doing so is important because this sector is at the forefront of the fight against the pandemic. We investigate the effect of the COVID-19 pandemic on nine Indian pharmaceutical firms and the pharma average. By employing an event study methodology, we find that the abnormal and cumulative abnormal returns are positive and statistically significant for the pharmaceutical industry during the COVID-19 pandemic. However, mixed results of abnormal returns are noticed when comparing our results at individual firm level. We also use lockdown as a result of COVID-19 as an event and examine the impact of the lockdown on pharmaceutical firms. We observe similar patterns of the positive effect of COVID-19 on pharmaceutical firms. Finally, to check the robustness of results, we use both event study and BHAR methods, and find consistency in our results.

From a policy perspective, the Indian government should be vigilant on price stabilization of pharmaceutical products during the pandemic and help the pharmaceutical firms either by providing subsidies or through reducing corporate tax and tariffs during the COVID-19 pandemic. As India is a leader in the world pharmaceutical products market, incentives from the government can increase the production of COVID-19 vaccines, which can further boost exports from the pharmaceutical industry.

Acknowledgments: The authors thank the Managing Editor, Professor Paresh Kumar Narayan, and two anonymous referees for their valuable comments and suggestions. Earlier version of this paper was presented in the $14^{\text {th }}$ Bulletin of Monetary Economics and Banking (BMEB) webinar. Helpful comments and suggestions from Dr. Susan Sunila Sharma and other participants are duly acknowledged. 


\section{REFERENCES}

Agarwalla, S. K., Jacob, J., \& Varma, J. R. (2013). Four Factor Model in Indian Equities Market. (Working Paper W.P. No. 2013-09-05). Indian Institute of Management, Ahmedabad.

Athreye, S., \& Godley, A. (2009). Internationalization and Technological Leapfrogging in the Pharmaceutical Industry. Industrial and Corporate Change, 18, 295-323.

Dev, S. M., \& Sengupta, R. (2020). Covid-19: Impact on the Indian Economy (Indira Gandhi Institute of Development Research Working Paper, No.2020-013). Indira Gandhi Institute of Development.

Devpura, N. (2020). Can Oil Prices Predict Japanese Yen? Asian Economics Letters, 1(3). https://doi.org/10.46557/001c.17964

Devpura, N., \& Narayan, P.K. (2020) Hourly Oil Price Volatility: The Role of COVID-19. Energy Research Letters, 1, 13683. https://doi.org/10.46557/001c.13683

Donadelli, M., Kizys, R., \& Riedel, M. (2017). Dangerous Infectious Diseases: Bad News for Main Street, Good News for Wall Street? Journal of Financial Markets, 35, 84-103.

Fama, Eugene F., \& French. Kenneth R. (1993). Common Risk Factors in the Returns on Stocks and Bonds. Journal of Financial Economics, 33, 1, 3-56.

Gu, X., Ying, S., Zhang, W., \& Tao, Y. (2020). How do Firms Respond to COVID-19? First Evidence from Suzhou, China. Emerging Markets Finance and Trade, 56, 2181-2197.

He, P., Sun, Y., Zhang, Y., \& Li, T. (2020). COVID-19's Impact on Stock Prices Across Different Sectors-An Event Study Based on the Chinese Stock Market. Emerging Markets Finance and Trade, 56, 2198-2212. https://doi.org/10.1080/154 0496X.2020.1785865.

He, P., Niu, H., Sun, Z., \& Li, T. (2020) Accounting Index of COVID-19 Impact on Chinese Industries: A Case Study Using Big Data Portrait Analysis. Emerging Markets Finance and Trade, 56, 2332-2349; https://doi.org/10.1080/154049 6X.2020.1785866

Iyke, N. B. (2020). Economic Policy Uncertainty in Times of COVID-19 Pandemic. Asian Economics Letters, 1. https://doi.org/10.46557/001c.17665

Kale, D. (2019). From Small Molecule Generics to Biosimilars: Technological Upgrading and Patterns of Distinctive Learning Processes in the Indian Pharmaceutical Industry. Technological Forecasting and Social Change, 145, 370383.

Kale, D., \& Little, S. (2007). From Imitation to Innovation: The Evolution of R\&D Capabilities and Learning Processes in the Indian Pharmaceutical Industry. Technology Analysis \& Strategic Management, 19, 589-609.

Kritzman, M. P. (1994). What Practitioners Need to Know About Event Studies. Financial Analysts Journal, 50, 17-20.

Mishra, A.K., Rath, B.N., \& Dash, A.K. (2020) Does the Indian Financial Market Nosedive Because of the COVID-19 Outbreak, in Comparison to After Demonetisation and the GST? Emerging Markets Finance and Trade, 56, 21622180.

Narayan, P. K. (2020a). Oil price news and COVID-19-Is There Any Connection? Energy Research Letters, 1, 13176. https://doi.org/10.46557/001c.13176 
Narayan, P. K. (2020b). Did Bubble Activity Intensify During COVID-19? Asian Economics Letters, 1(2). https://doi.org/10.46557/001c.17654

Narayan, P. K. (2020c). Has COVID-19 Changed Exchange Rate Resistance to Shocks? Asian Economics Letters, 1. https://doi.org/10.46557/001c.17389

Narayan, P. K., Phan, D. H. B., \& Bannigidadmath, D. (2017). Is the Profitability of Indian Stocks Compensation for Risks? Emerging Markets Review, 31, 47-64.

Narayan, P. K., Ranjeeni, K., \& Bannigidadmath, D. (2017). New Evidence of Psychological Barrier from the Oil Market. Journal of Behavioral Finance, 18, 457-469.

Phan, D.H.B., \& Narayan, P.K. (2020) Country responses and the reaction of the stock market to COVID-19 - a Preliminary Exposition. Emerging Markets Finance and Trade; 56(10), 2138-2150. https://doi.org/10.1080/1540496X.2020.1784719

Prabheesh, K.P. (2020). Dynamics of Foreign Portfolio Investment and Stock Market Returns During the COVID-19 Pandemic: Evidence from India. Asian Economics Letters, 1. https://doi.org/10.46557/ 001c.17658.

Ramelli, S., \& Wagner, A. F. (2020). Feverish Stock Price Reactions to COVID-19 (CEPR Discussion Papers, 14511). C.E.P.R.

Rath, B.N., \& Akram, V. (2020). Does COVID-19 Outbreak Cause Spot Electricity Price Discovery in India? Journal of Public Affairs. https://doi.org/10.1002/ pa.2439.

Seungho, B., Mohanty, S.K., \& Glambosky, M. (2020). COVID-19 and Stock Market Volatility: An Industry Level Analysis. Finance Research Letters, 37, 101748.

Sha, Y., \& Sharma, S.S. (2020) Research on Pandemics Special Issue of the Journal Emerging Markets Finance and Trade, 56, 2133-2137; https://doi.org/10.1080/154 0496X.2020.1795467

Sharma, C. (2012). R\&D and Productivity in the Indian Pharmaceutical Firms. Journal of the Asia Pacific Economy, 17, 332-342.

Sharma, S. S. (2020). A Note on the Asian Market Volatility During the COVID-19 Pandemic. Asian Economics Letters, 1. https://doi.org/10.46557/001c.17661

Sharma, S.S., \& Sha, Y. (2020) Part A: Special Section on COVID-19 Research. Emerging Markets Finance and Trade, 56, 3551-3553. https://doi.org/10.1080/154 0496X.2020.1858617

Shen, H., Fu, M., Pan, H., Yu, Z., \& Chen, Y. (2020). The Impact of the COVID-19 Pandemic on Firm Performance. Emerging Markets Finance and Trade, 56, 22132230.

Yan, C. (2020). COVID-19 Outbreak and Stock Prices: Evidence from China. SSRN Electronic Journal. https://doi.org/10.2139/ssrn.3574374. 